\title{
Three myths about BDA Indemnity
}

\section{Dr Russell Heathcote-Curtis}

Dental Advisor, BDA Indemnity

Myth: I have been told that BDA Indemnity is backed by insurance and therefore it must be a claims-made product - on leaving I will need to purchase run-off cover and there will be an excess I have to pay for any claim against me. Is this true? A. The BDA Indemnity policy is not claims-made. We have insisted that the indemnity is provided by an occurrencebased policy, which is widely recognised as being the gold standard, avoiding the gaps frequently associated with claims-made cover. This is the same offering as the three traditional MDOs. It offers the best longterm protection, security and continuity of cover. An occurrence-based policy provides perpetual indemnity (including when you have retired) for treatments provided during your period of membership. Occurrencebased indemnity is best for dentists and best for their patients.

When writing the policy, the BDA insisted there should be no compulsory or voluntary excess (or deductible) payable on a legal expenses claim to the value of $£ 250,000$ per claim, or on a claim of negligence which has cover of $£ 10$ million pounds per claim or aggregate in a policy year. As the policy is occurrence-based there is no need for run-off cover unlike some other insurance policies.

\section{Claims-made policies}

A typical claims-made policy provides indemnity for incidents that arise out of treatments provided within the period of insurance and are notified within the period of insurance. If you do not renew this type of policy, the insurer's liability comes to an end. Claims relating to treatment may arise many years after the actual treatment took place so there is a need to have adequate cover long after you have left this type of insurance cover. This is called run-off cover.

\section{Run-off cover}

Run-off cover is required for claims-made policies. This provides an extended reporting period to indemnify you against claims relating to previous years that are made after you leave that policy.

You will need to check with your current insurer how long the run-off cover they provide is and how much it will cost.

Insurers are not obliged to offer you this cover (it is at their discretion) but if they do, the charge could be between $100 \%$ to $150 \%$ of the previous year's premium. The longer you work under a claims-made policy, the longer the period that needs to be covered by separate runoff cover; the premium consequently becomes more expensive with each passing year.

The GDC insists that you have adequate indemnity to cover past as well as current periods of practice.

Myth: Won't a policy of insurance allow the insurer to use its discretion not to assist the policy in the same way that medical defence organisations sometimes use their discretion to deny assistance?

A. The BDA Indemnity policy is occurrencebased, but because it is a contract, once we accept you as a member you know you will be assisted for any incident covered by the policy. There is no discretion that stops us from assisting you.

We have tried to make the policy as inclusive as possible of all the dental treatments that are currently provided. This is why, if you are on the implant grade for example, it also covers (at no extra cost) performing sinus lifts and bone grafting in the maxilla and mandible. The policy also covers dermal fillers and use of botulinum toxin as long as the treatment is above the lower border of the mandible (again without an extra charge).The policy extends to cover the vicarious liability of practice owners towards their employees, like nurses and receptionists to self-employed dentists who provide dental services in the practice. Certain conditions apply in relation to ensuring the associate, whilst they were working at the practice, had appropriate indemnity cover and the practice had a contract for the associate.
Myth: It's difficult to make a choice on which provider I should choose

Here are some questions to ask before you choose which indemnity provider to use.

\section{Ask the insurance companies}

$\rightarrow$ Why claims-made not occurrencebased?

$\rightarrow$ How many years run-off cover do I get?

$\rightarrow$ Will that be sufficient cover?

$\rightarrow$ How much will it cost me to buy a longer period of run-off?

$\rightarrow$ Can I be sure that you will offer me run-off cover or is that provided on a discretionary basis?

\section{Ask the medical defence organisations}

$\rightarrow$ If a claim is made against me a few years after I retire will you guarantee that you will cover me?

$\rightarrow$ Can you give me an example of an occasion when you have exercised your discretion to indemnify a member when an insurance policy from another provider would not have covered them?

Are you thinking of changing to a new indemnity provider?

Ask your existing provider if they have got the expertise to advise you on:

$\rightarrow$ NHS disputes with the commissioners -

\section{BDA does}

$\rightarrow$ Employment matters - BDA does

$\rightarrow$ Provide detailed compliance support for practice inspections from regulators like CQC, RQIA, HIW - BDA does

$\rightarrow$ Business matters - BDA does.

For further information visit www.bda.org/ indemnity

This policy is arranged by the British Dental Association and underwritten by Royal \& Sun Alliance. The British Dental Association is an appointed representative of Lloyd \& Whyte Ltd. Lloyd \& Whyte Ltd is authorised and regulated by the Financial Conduct Authority (FCA). The FCA does not regulate the advice you receive with regards to advisory, case management and indemnity support provided by the BDA. *

https://doi.org/10.1038/s41404-020-0388-6 